placed in a basin of boiled water and cleaned and replaced in the towel after use.

General precautions. - Here it is the duty of the surgeon to devote "extreme attention to the avoidance of any possible contamination," and I do not think antiseptics should be encouraged in this part of the work if it will encourage surgeons to devote less attention. Sponges I have not seen used for some years as the great difficulty is undoubtedly in completely sterilising them. Gauze, as I have described, cut in definite sizes and infolded and sterilised, is infinitely safer. I have had difficulty with imperfectly sterilised catgut but not for some time. It is now prepared by Lockwood's method. Gut for ligature and silkworm gut for suture, and silk and celluloid thread, all well boiled before use, for pedicles and buried sutures have proved satisfactory, but undoubtedly gut is difficult to make aseptic. Gauze will never replace drainage tubes, but it is better to have a gauze packing in an abscess cavity than simply to open and to put in a tube. Such a case should be well opened and dried out with gauze, all débris removed, and then packed with gauze. This is better surgery than simply opening and putting in a tube. Better still is to open freely every recess of the abscess, to wash with saline, or saline and peroxide of hydrogen 5 per cent., and to dry, and then to touch up the interior with pure carbolic acid and to fill the whole wound with methylated spirit; dry now thoroughly with gauze and pack for 48 hours; remove, wash around with spirit, dry, and close. This is the most effective method I have yet come across for tuberculous abscess. The advantage Mr. Watson Cheyne claims for medicated dressings is a further argument in favour of strict asepsis and attention to detail. It ought to be taught that whenever a dressing shows the least suspicion of staining it should be immediately covered by a fresh pad or the dressing changed-knowing that, if this is neglected, the risk of sepsis is too great. On the other hand, surely Mr. Watson Cheyne does not teach that if the dressing contain an antiseptic the dressing need not be changed, "nor does the sepsis spread back to the wound." That "pus means sepsis" should be accepted as a good working maxim. There are a few further details on aseptic methods which $\mathrm{Mr}$. Watson Cheyne has omitted. I would first mention the prominent part that methylated spirit plays in the subsequent dressing of a wound, and the use of rubber gloves, especially in dealing with septic cases, as a protection to the surgeon's hands and in abdominal operations. Finally, it is well known that sterile saline solution is largely used in aseptic surgery for its unirritating qualities. I experimented with baths of lot. ac. carbol. 1 in 100 ; lot. hyd. perchlor. 1 in 2000 ; and lot. boric and saline in normal solution, immersing crushed hands and ulcers in them. The saline I found to cause the most rapid granulation and cicatrisation of the wound. Aprons and gowns are essential and need not be discussed. The nurse's position at an operation should be perfectly defined and her duties detailed. There should be one whose duty it is to sterilise the instruments and dressings-the instrument sister-who occupies this place only ; another to hold the basin containing the sterile mops for the surgeonnot to hand them to him; another to attend to the receiver for soiled mops, dressing, \&c. ; and, lastly, one to look after irrigation: all to have their sleeves rolled up beyond the elbows and to have their hands and arms well washed and clean. That nurses will take all the trouble required I have found from experience, but they must be taught it and have the example of consistency set them, the surgeon not going into his bag and doing a lot of thoughtless things after having sterilised his hands.

That the aseptic method can be successfully carried out in private practice I have no doubt, as all that is wanted is a kettle of boiled and one of boiling water and plenty of freshly laundried towels. The rest is easy and all a matte of routine, detail, and constant watchfulness. The work that Lord Lister began in Glasgow cannot stand still, and it seems to me that the great benefits that were commenced by him then are finding their logical conclusion and perfection in the very attention to detail and "trouble " he then advocated and practised and are more certainly likely to be accomplished by the steam sterilisation of dressings and instruments and the strict attention to aseptic detail, instead of taking one's chance of the medicated dressings being sufficient to kill every organism that may come their way.

I am, Sirs, yours faithfully, JAMES LAURIE, M. B., C.M. Glasg.

\section{POLYMASTISM AND POLYPARITY.}

\author{
To the Editors of THE LANCET.
}

SiRs, - As the subject of multiple pregnancies is under discussion in your columns, it occurs to me that it may interest your readers to have their attention called to certain relations between polyparity and polymastism which have not hitherto been noticed. Both these anomalies may, I think, be ascribed to reversion. As I. G. St. Hilaire has remarked "Un individu remarquable par des formes anomales, tombe presque toujours par cela même dans les formes normales d'un autre âge, d'un autre sexe, ou d'une autre espèce." I is under the last of these headings that the anomalies I am considering may be classed.

Among mammalia numerous mammæ in two parallel series are the rule, and for only a single pair to be found-as in mankind-is most exceptional. Now there is a certain relation between the number of mammx met with in the mature female and the number of young brought forth at a birth, the former being, as a rule, twice as numerous as the latter. It accords with this, that polyparity is the rule among mammalia and that the human uniparity is exceptional. It is a curious fact that in early embryonic life even human beings have multiple mammary rudiments-arranged just like the mammæ of most adult mammals-although all but a single pair of them, as a rule, subsequently abort. As the individual development is generally regarded by biologists as a kind of epitome of that of the race, it may be concluded from this and from other considerations, that human polymastism is a reversion to a primitive condition in which many glands were developed and many young were brought forth at a birth, as is now the case with most mammalia. The transition from polymastism to bimastism may be seen going on in lemurs, whose inguinal and abdominal mammæ are disappearing, so that only one or two pairs of pectoral mamma are now well developed; and this change has been correlated with diminution in the number of young brought forth at a birth.

Thus it seems certain that the reduction of the primitively multiple human mammæ to a single pair has been brought about in consequence of the change from polyparity to uniparity. Other changes consequent on this diminished fertility have been the evolution of the single (unilocular) human uterus from a primitively double form. Some biologists believe that the origin of menstruation may also be traced to this diminished fertility - at any rate, non-menstruating mammals are far more prolific than menstruating ones. In this connexion it may be mentioned, as Ballantyne and others have pointed out, that the ovaries of very prolific polyparous women, in whom twins are common, are generally of the foetal type, especially in respect to the immense number of ovisacs they contain.

The question has often been asked whether polymastic women are more liable than others to beget more than a single child at a birth? To this it may be answered that of 70 polymastic women in Leichtenstern's list three had given birth to twins, or 4.3 per cent., whereas the average proportion of twins among British women is only about 1 per cent. In a remarkable case of hereaditary polymastism recorded by Marie this anomaly was concomitant with frequent twin-births and excessive prolificacy for several generations. Viewing the matter in this light, let us seek an answer to the question. What is the greatest number of children a woman may bring forth at a single birth? As I have pointed out in my monograph on "Diseases of the Breast," there are good reasons for believing that the human atavus had at least seven pairs of mammæ on the ventral aspect of the trunk, of which the present normal pair alone survive. If, therefore, we may answer our query by an appeal to this indication, it would appear that as many as 14 children might possibly be brought forth at a birth. I should not care to deny offhand the absolute impossibility of such an occurrence. Among the ancients Pliny says that as many as 12 at a birth had been noted, and others even 15 ; but Aristotle would not admit the possibility of more than five. In comparatively modern times, however, apparently well-authenticated instances of eight at a birth, seven at a birth, and six at a birth, have been reported. Altogether, it seems desirable to keep an open mind as to the maximum possibility.

I am, Sirs, yours faithfully,

Clifton, Bristol, Feb. 10th, 1903.

W. ROGER WILLIAMS 


\section{THE RISE OF BLOOD PRESSURE IN LATER LIFE.}

To the Editors of THE LANCET.

StRs,-If the meeting at which Professor,T. Olifford Allbutt read his interesting paper on the Rise of Blood Pressure in Later Life was not very numerously attended nor his views then very fully discussed, it cannot be said that the rostrum of your columns has not since then been sufficiently and efficiently occupied by those taking an interest in the subject. The peripheral factors in the production and maintenance of increased blood pressure as life advances have been fully dealt with, although the situation and mechanism of the process have been the subject of divergent or different views for the opinions expressed differ rather than diverge. While Sir William $H$. Broadbent and Sir R Douglas Powell have stood stoutly by the theory of capillary resistance Dr. Harry Campbell, sustained by the important dead-house pathology of Dr. William Russell, sees in bespasmed arteriole the efficient cause of the ultimately persistent process-in the hypertonus of Dr. Russell the cause of the arterio-sclerosis of later life. We must all feel grateful to Professor Allbutt for having mooted a subject in the felicitous manner so peculiarly his own which has elicited so much fact and so much hypothesis. It is not because I can add much of moment to what has already been said that I venture to crave your permission to occupy the momentarily vacated tribune of your journal, but because one or two points which my own study has impressed upon me have not so far been fully brought out in the discussion. These are not contrary, I think, to the spirit of Professor Allbutt's argument. In discussing the subject of the rise of blood pressure in later life, it appears to me that the cardiovascular changes secondary to renal disease should be excluded from consideration, except in so far as cardiac failure may induce circulatory renal disturbance, and the diagnosis of these distinct states is not a difficult matter. Excluding, then, cardio-vascular change secondary to kidney disease, we find as life advances a hyperplasia of the intima of the vessels and of the interstitial tissue of the heart, with some hypertrophy of the muscular elements in both these situations, a hypertrophy which in the case of the heart ultimately yields to the persistent peripheral obstruction, where the vessel, less active and less organised than the central organ, usually maintains its more sluggish muscular hypertrophy longer. The change may or may not, as we know, be associated with calcareous deposition. When this occurs, however, the more or less rigid vessels may have an abnormal patency and then the muscular coat, far from being hypertrophied, may, indeed, be atrophied, for it is then not over-exercised but under-exercised. Such a vessel, when the deposited lime-salt is scattered, as it usually is, may, as Sir William Broadbent remarks, be associated with a comparatively soft and compressible pulse, even in old age. The question then is, Does cardio-vascular hypertrophy precede or follow the connective tissue hyperplasia? It is unfortunate that the point cannot be determined during life, and after death both states are found in association unless atrophic muscular degeneration has supervened. That both are present in later life, when hypertonus has become persistent-when spasm, if antecedent, has passed into arterio-sclerosis-will not, I suppose, be disputed. It is only, I would suggest, by a more systematic dead-house research, with histological examination of the structures involved at all ages and in cases uncomplicated by gross organic disease, that the point can be settled. Such an investigation, so far as I am aware, has not yet been made and our argument must of needs, therefore, at present be largely hypothetical. So far as I may with diffidence express an opinion, I am inclined to believe that if muscular hypertrophy be primarily due to active and sustained hypertonus it is soon increased by having to deal with the more persistent inelasticity of connective tissue hyperplasia and that such connective tissue increase is, therefore, an active cause in heart and vessels of difficulty in propelling and conducting the circulation as life advances and provocative of the compensatory changes necessary to deal with it. This, then, is one point which I desired to emphasise. The other is, that, in my belief, the study of the peripheral physiology and pathology of the vessels has distracted attention in a measure from senile changes in the heart capable of being generated by its own activity, apart from the abnormal labour thrown upon it by peripheral obstaclethat is, that the nervous, muscular, and hæmic factors which together go to produce the functional unit of cardiac action cause changes in the organ itself, dealing as it does with the emptying of its chambers (the blood weight) and with the stress of the emotions, aggravated or not, as the case may be, by imprudences in diet and exertion. Important as the study in the living of these questions is Professor Allbutt in his reply to Sir Douglas Powell has shown that he in no wise desires to minimise the value of anatomical research, which has still much to contribute towards the elucidation of this subject. The physician cannot yet answer these questions, as Faust, also quoted by Professor Allbutt in his last letter, solved an analogous psychological problem :-

\section{Still dost thou ask, why in thy breast \\ The sick heart flutters ill at rest? \\ Why a dull sense of suffering \\ Deadens life's current at its spring? \\ From living Nature thou hast fled}

To dwell 'mong fragments of the dead."

We are still doomed, I fear, to dwell long among fragments of the dead before we shall be able adequately to explain the progressive pathology of the living processes causing a rise of blood pressure in later life.

I am, Sirs, yours faithfully, ALEXANDER MORISON.

\section{To the Editors of THE LANCET.}

SiRs, - I have read the correspondence on the Rise of Blood Pressure in Later Life which has already appeared in THE LANCET with much interest, and venture to ask your permission to make a few remarks with special reference to the relationship of general arterial hypertonus to the blood pressure. This relationship is undoubtedly a very complex one, and personally I am quite satisfied that when the walls of the radial artery are tightly contracted the pressure within may be either considerably increased or greatly lowered.

There is no doubt that the arteries respond very precisely to the action of toxic substances circulating in the blood and in such circumstances their calibre is diminished. This may be called toxic arterial contraction or hypertonus, and the condition is present in all cases of auto-intoxication, whether arising from poisons which are absorbed from the alimentary canal or due to certain chemical changes occurring in the tissues as a result of abnormal metabolism. Anyone may suffer from this kind of hypertonus and during the time that the arteriole contraction is present $I$ believe that the blood pressure is almost invariably raised in the larger arteries. Marked diuresis for several hours is often a striking feature of this transient toxæmia, and when the toxins are eliminated the calibre of the radial artery is found to be enlarged. Dr. Harry Campbell's explanation of the greatly increased secretion of urine in such cases-that while the systemic arterioles are contracted those of the renal field are dilated-may be correct but it does not always apply. Thus in the grave anto-intoxications of pregnancy which sometimes culminate in eclampsia hypertonus is an early and persistent feature and is accompanied by a marked rise in the blood pressure. When such symptoms are present the secretion of urine is notably diminished and as hypertonus and increased pressure become more pronounced the urine may be suppressed altogether. In myxœdema and cretinism, which are typical auto-intoxications, hypertonus is always present, and the increased blood pressure in these diseases is associated with a lessened urinary secretion.

The point which I wish to emphasise, however, is that toxic hypertonus is seldom present for any length of time without some augmentation of the blood pressure, and I believe that the explanation of this is to be found in the fact that in these cases the obstruction to the flow of blood lies not only in the arterioles but also in the capillaries. Arteriole contraction alone, as it is observed in cases of non-toxio hypertonus, is certainly very often unaccompanied by any increase in the blood pressure, and the implication of the capillaries in the area of peripheral resistance must be regarded as a factor of primary importance when the pressure is considerably raised. It is well recognised that the capillaries are much more sensitive to the action of toxins than the arterioles.

Non-toxic hypertonus is a prominent feature in certain 